médula de nuestra psiquis, que tal vez castigada por algún dios cruel o vengativo fué condenada a ser la eterna solitaria, a quedarse en ese balbuceo de aproximación que le ofrecen las palabras, las artes o el amor. Y en esta conciencia trágica de soledad se tienden entonces los telones y las bambalinas, y a todos los sones de la orquesta rueda la vida de la gran ciudad.-M A R T A VERGA R A.

\title{
¿Hacia dónde va la poesía?
}

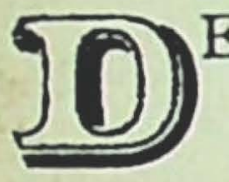

ESPUES de la guerra del 14 que desoló Europa y cuya repercusión económica llegó hasta los pueblos de Sudamérica, convirtiéndolos automáticamente en colonias del más poderoso pueblo que jamás registró la historia de la humanidad, el pensamiento, la sociología, el arte, no podían conservarse estacionarios, sino contexturarse de acuerdo con las urgentes necesidades contemporáneas. La mente del hombre, estática hasta entonces, se motoriza hacia radios de más campo de acción, donde solamente se agita un problema básico. La confusión, producto de la misma guerra, ensombreció un ciclo corto de la historia. Dentro del caotismo existente, no podía vislumbrarse un pensamiento analítico, creador y constructivo, sino un pensamiento y un arte cuyas células traían la negación de su ser.

La noche inmensa de la guerra no permitió que los hombres pudieran ver más allá del abismo. Los caminos de la vida estaban nitroglicerinados. El panorama europeo estaba encendido de locura, barajándose las ideas, tanto políticas como estéticas, dentro del más profundo y absoluto individualismo. El principio individualista en su aspecto clínico. Sólo después del año 17 en que alumbró una estrella la aurora de la hun:anidad, vemos la transformación material y espiritual por medio de las corrientes que determinan la evolución económica y social de la humanidad. Desde entonces los problemas no son de carácter privado, sino público. El individuo es un átomo de la gran maquinaria, célula de un cuerpo organizado que cumple su función. El mismo aindividualismo genial »-de que nos habla Cocteau-cumple su misión dentro de la sociedad, jamás fuera. Su aislamiento es su propia muerte. Por ejemplo, Francia fué un centro de experimenta- 
ción en el que se debatieron las concepciones artísticas más heterogéneas y personalistas. De ello no queda sino un recuerdo de sabor deportivo. La mente se fatigó tanto que hubo una pequeña conversión hacia el clasicismo cristiano. Tantas escuelas estéticas, de las cuales solamente quedan los nombres, todavía subrayados en las mentes femeninas de los puritanos artistas. Pero sería también absurdo negar que sirvieron para abrir el camino de la reacción. No fué larga la espera. Aquí no hubo un salto, ni una trasmutación de valores: el rigor de los acontecimientos sociales fué venciendo las etapas por la que habría de pasar el arte de su función burguesa a marxista, vale decir socialista. El arte está evolucionando hacia la ciencia, condicionada por la vida. Esto es lo que no aceptan los viejos teorizantes de las escuelas estéticas que creen que la vida está determinada por el arte. Claro, su manera de ser social es ésta, y es la que determina su conciencia.

Las ondas de esta nueva conciencia artística, revolucionaria y marxista, repercuten no solamente en las élites literarias, sino que ha tiempo llegaron al pueblo, donde está su verdadero porvenir. $Y$ nadie negará que todo lo que llega a la sensibilidad de las clases privilegiadas de la inteligencia y del pueblo, es obra verdadera, humana. De allí el poeta canta desde lo más hondo del hombre; igual cosa sucede en todas la demás manifestaciones del pensamiento. La otra poesía neo-sensible es producto de cenáculo, donde el egoísmo es la característica sustantiva. Si buscamos la razón de su ser, no la encontramos. "En el arte, como en el destino hay algo que no se ve»-dice un poeta, de los más inteligentes metafísicos. Si una obra de arte emociona, es porque en ella hay algo que se ve, que se siente, y si sabe llegar a la sensibilidad de todos los hombres, es social. Sí, humana. Para el hombre nada se le oculta. Sólo aquéllos que siguen pensando en el cielo hasta la misma realidad cotidiana no la ven, $y$ de tal forma se producen.

Insistimos en que el arte surge como expresión de la vida. Por eso desempeña un papel importantísimo en la historia de la humanidad, indicando por su evolución la ascensión de la producción humana. El artista debe estar con su época, y ésta no es de fantasías, ni de sentimientos que carecen de claridad. El arte de la post-guerra se distingue por su obscuridad, y es además fundamentalmente romántico y tan pacífista que está degenerando en académico. Esto es, un arte decadentista. Sólo un laboratorio donde se puede analizar 
la nueva creación, mostrar las raíces sociales, negativas y positivas, podría hacernos encontrar un arte con fines e ideales humanos. Obvio es decir que humanitarismo no significa paz.

En el alborear de esta nueva conciencia artística queda aclarado el fracaso de la fórmula exclusivista del \&arte por el arte». El arte que no hace pensar en nada, que no tiene un fin, un ideal, ¿cómo puede pedir que se le tome en cuenta? ¿Acaso nos olvidamos de que es el materialismo histórico, y sólo el materialismo, el que marca orientaciones nuevas y hace las revoluciones? Tal vez un momento se le valorizó; pero fué en un solo momento, cuando los hombres de este lado de América pusieron su esperanza en el Occidente; mas cuando se dieron cuenta que era también enemigo de la verdad, buscaron en ellos mismos un pensamiento, un arte que redimiera para siempre su papel de negación por uno de acción.

¿Qué nos queda ahora que vemos el proceso que sufre el arte inútil o sea el arte por el arte, en Europa? Allí se engendró, creció en América, y luego va a morir a la misma Europa. Nadie niega que las estéticas «vanguardistas» tuvieron por matriz la guerra. Fué el producto de los gases asfixiantes y de los «shrapnells». La exaltación de los "ismos» brotó de mentes enfermas. Crecieron en el fondo de la muerte; no podían airearse con la vida, si estaban determinados por elementos psico-patológicos. América, continente ingenuo e infantil, como tal imitador de las malas costumbres, vió con lupa de aumento la estética y el arte en general, haciéndose cómplice y disidente. Y prendió mejor en América, si tenemos en cuenta la pereza de nuestros poetas para analizar y hacer obra que requiere haber vivido muchas vidas $y$ haber estudiado con disciplina. Sobre todo en América estamos acostumbrados a vivir de la roña europea. La intuición no es suficiente, sino para llegar al error flagrante. De allí el desprestigio de nuestros poetas, que llegan hasta el sarcasmo de la compasión, cuando quieren incorporarse al ritmo moderno de la civilización.

El poeta, en la cabal expresión de la palabra, tiene un papel importantísimo que realizar: unir a los hombres; si no, se hace traidor a la humanidad. Quien no siente la palpitación del mundo y la interpreta en su verdadero sentimiento de justicia, no puede denominarse hombre. $Y$ estamos en la conquista del hombre. El poeta antes que todo tiene que ser hombre. Es cierto, en nuestro medio, el poeta, el artista, es un adolescente, y su palabra nunca podrá expresar el senti- 
miento colectivo, y aquellos que rompiendo su torre de marfil van al pueblo son los constructores de una mejor vida y de una cultura.

La joven América Latina no puede traducir su pensamiento sino en verso. La prosa, la novela, la historia, son productos de madurez. Y nunca la poesía había alcanzado mayor esplendor en América que en nuestros días. Veamos la poesía de un sector: México. Tomamos este país por ser el que más se caracteriza en su producción literaria. Otros países están también impulsados por la misma marcha-Perú, Argentina, Cuba, Bolivia, Venezuela-. Fenómeno que tendrá que operarse en los demás pueblos a medida que el imperialismo haga presente su fuerza bruta y adquieran conciencia de responsabilidad histórica.

En México, como en todos los demás pueblos del Río Bravo para el Sur, pugnan dos corrientes. Una que busca la poesía; la otra, el pensamiento como fuerza motriz y la poesía. De este modo la crítica los ha denominado con los términos de derecha y de izquierda. Al presentar a estos poetas no nos guía ningún afán partidarista, sino el deseo de que sean valorados con justicia, especialmente en esta hora en que América entra a un examen de conciencia.

EXPRESION DE LOS POETAS DE DERECHA

Se canta en el poema, por tristeza y olvidanza, la gota perenne de una estrella sobre la estalactita de la esperanza. (Carlos Pellicer.)

Los nopales nos sacan la lengua pero los maizales por estaturas con su copetito mal rapado y su cuaderno debajo del brazo nos salen con sus mangas rotas.

Pos natal total inmersión para la ahijada de Colón con un tobillo en Patagonia y un masajista en Nueva York. (Su apendicitis labró el Canal de Panamá.) (Salvador Novo.)

Afuera, el ruido fresco de la fuente mojaba la arena del silencio y el canto sin color de las cigarras.
DE LOS DE IZQUIERDA, O AMERICANOS

TRENES MILITARES

que van hacia los cuatro puntos

al bautizo de sangre

(cardinales,

donde todo es confusión,

y los hombres borrachos

juegan a los naipes

y a los sacrificios humanos;

trenes sonoros y marciales

donde hicimos cantando la Revo-

(lución.

Allá lejos

mujeres preñadas

se han quedado rogando

por nosotros

a los Cristos de Piedra.

(Maples Arce.)

Un disco anaranjado

es el sol,

que cuelga sobre el vasto tumulto

de overol.

(uniformado

(Martin Paz.) 
Una paloma del jardín

se puso a picotear el tiempo

en el oro granado del maíz.

(Jaime Torres Bodet.)

Y vendrán bruscos los deseos

quizá me sientan palpitar;

arderán inútiles sus labios

de jacinto y de azahar.

(Marfa del Mar.)

\section{Las almas}

caminan sobre el 1 ío

para no tocar el polvo con los pies. (Kin Taniya.)

Tu voz, hoz de eco,

es el rebote de mi voz en el muro, $y$ en tu piel de espejo

me estoy mirando mirarme por mis

por mis largos segundos.

(Argos,

\section{y me dejas}

sin más pulso ni voz y sin máscara, sin máscara como un hombre des(nudo en medio de una calle de miradas. (Xavier Villaurrutia.)

Por las cortinas del alba asoman palomas blancas, otras de overoles grises

y las negras, tipográficas.

\section{Jazz}

Venganza de serpiente, el saxofón adormece a las flautas

en el mercado negio de la orquesta. (B. Ortiz de Montellano.)

LAS HUELLAS de los pies de sus

Han cubierto su alcoba (amantes con un tapiz de peregrinaciones.

La arcilla de su seno

Está llena de huellas digitales, Y todo su cuerpo de jeroglíficos

De colibríes, besos

De sus amantes niños....

$$
\text { (José Juan Tablada.) }
$$

Por los deshielos de abril confusamente respiro
Cada grano que siembras, campe-

-dolor, dolor-,

una esperanza más que entierras bajo este régimen traidor.

(M.D. Martínez Rendón.)

Campesino

que vives en derruida cabaña

espiando el horizonte para ver si la

afila la guadaña

(lluvia se aproxima;

que va a lucir el sol sobre la cima,

y es hora de segar;

ya está el grano maduro

y la mano del patrón ya quiere el

Siega pronto esa mano

(grano.

que te quiere robar.

(Germán List Arzúbide.)

SOLDADERA

porque en esta hora grave,

muchas veces en cinta

has cargado el 30-30,

has compartido nuestras hambres y has cantado con nosotros

el himno de sLa Valentina.

bajo la marquesina de las balas....

Porque nos pariste los hijos en las

o en la cárcel;

(calles

porque te poseyeron los triunfadores y te perdimos en los botines de (todos los desastres, cuando llevas nuestros hijos en tus (carnes; porque te llenaron de excreciones y te colgaron de los árboles, y porque muchas como tú se que-

a mitad del camino.

(daron podridas

\section{(Baltasar Dromundo.)}

CAMPESINO SABIO

Sabio tú, que escuchas la voz de la Naturaleza, que conoces la belleza de Dios....

Sabia tu mano

que no yerra,

que saca el grano

de la tierra. 
el calofrío sutil

de cada vez que te miro. (Alfonso Reyes.)

Una estrella canta

en el cielo

su sonata

de luz y silencio.

(E. González Martínez.)

Llegabas por la noche

sola

como una estrella,

como una ola....

(José María Benites.)

EL OJO DE AGUA

Delicia de las diez de la mañana, baño de agua tibia y clara

y azul y con sabor de lágrimas.

(Gilberto Bosques.)
Sabia tu vida, jornalero

que es florida

como el potrero.

Sabio tu pudor

sano,

sabia tu boca que no bebe sudor de tu hermano.

Sabia tu mente pura

llena de propia luz, que sin conocer la escritura sigues las leyes de Jesús.

(C. Gutiérrez Cruz.)

Pasan las ovejas cubiertas de lana. $\mathrm{El}$ pastor las sigue desgarrado $\mathrm{y}$

A ellas Dios las viste, (mudo.

al pastor el Amo lo deja desnudo. (José Rubén Romero.)

Ahora podemos preguntarnos ¿hacia dónde va la poesía? Los que militamos en las filas socialistas tenemos una sola respuesta categórica que dar. Creemos firmemente en la emancipación del pensamiento y el arte colonialistas, cuya expresión genuina es el «arte por el arte». El privilegio de la inteligencia es una fuerza cuando está al servicio de un ideal, por eso nuestro arte se colectiviza para determinar la transformación de una época, no solamente desde un punto de vista cultural, sino también político. Y la poesía en América es tal vez el signo más elocuente del nacimiento de una cultura nuestra, de contenido económico y político. Aunque Roberto Meza Fuentes lo niegue. Juicios tan apriorísticos y venidos de uno de los mozos de más claro talento, de quien las juventudes, por su obra de acción anterior, esperaban les señalara un derrotero, desconsuelan. No podemos creer que sufra un error histórico y se deje llevar por las sutilezas de los románticos, y que negando el aporte constructivo de la nueva pcesía política, niegue la crisis de la civilización capitalista, cuya agonía nos presenta Europa, donde nacen y mueren escuelas estéticas cuya antítesis es el arte político. Arte y política son cosas consustanciales. Negarlo es simplismo (1).

(1) Véase el comentario que hace R. M. F. a El hombre de estos años en El Mercurio del 13 de Abril. Si tomamos en cuenta la opinión de Meza Fuentes es porque coincide con la de no pocos escritores de Santiago. Ejemplo, Alone, crítico oficial de La Nación, los jóvenes poetas Seguel, Rosamel del Valle, y con ellos todos los nuevos poetas. 
Nuestro arte va a buscar la realidad social, a descubrir una cultura americana, no a inventarla. Este es problema fundamental para toda mente realista que sepa ver con claridad. América no le debe absolutamente nada a Europa, a no ser a aquellos occidentalistas débiles y confusionistas, cuyo desconocimiento de la realidad los hace sentimentalmente románticos. Así en poesía como en política, sobre todo en política.

Sólo creándonos una cultura, un arte propio, sin influencias ajenas, podremos medir el desenvolvimiento, el desarrollo, la fuerza continental de nuestros pueblos.

Una cultura, un arte americanos, del pueblo y para el pueblo, se convertirán en universales. Ahí donde el hombre encuentra su expresión está la poesía iluminada for la creación del pensamiento humanista. La poesía así con energía, fuerza y carácter nos está señalando el camino que abre a la cultura de la humanidad. Crear una poesía varonil americana, cuanto más nuestra sea, tendrá valor de contribución para la historia. Primero es el pensamiento, después es la belleza. El pensamiento no tendrá otra forma de expresión artística que ésta: americana en su raíz. «El porvenir está en el cerebro. Después vienen los músculos»-dice Gladkov. -SERAFÍN DELMAR.

\section{El panorama de Max Daireaux}

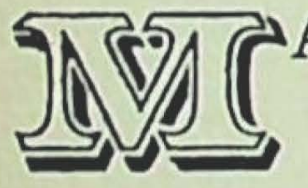

AX Daireaux, escritor francés hijo de americana, ha publicado un panorama de la literatura hispanoamericana (1) que merece en realidad un detenido comentario. Es un esfuerzo considerable, no se podría negar; pero sus deficiencias son también considerables. $\mathrm{El}$ autor revela conocimiento global de la literatura americana; comprende cuáles son los rasgos característicos de este proceso literario y hasta trata algunas figuras con extraordinaria elevación de miras y con verdadero dominio de la materia. Pero en lo particular yerra con frecuencia, como se verá más adelante. Recoger todos sus yerros nos ocuparía demasiado espacio. Nos conformaremos, pues, con examinar los que ha cometido el autor al mencionar a los escritores chi-

(1) Ediciones Kra. París, 1930. 